\title{
The variables related to public acceptance of evolution in the United States
}

\author{
Benjamin C Heddy ${ }^{1 *}$ and Louis S Nadelson ${ }^{2}$
}

\begin{abstract}
Background: The current study explores variables related to public acceptance of evolution in the United States by state. Data on acceptance of evolution, religiosity, science, technology, engineering, and mathematics (STEM) degree attainment, educational attainment, high school dropout rate, average teacher salary, and gross domestic product (GDP) per capita were analyzed for the 50 states.

Methods: Employing secondary data analysis, bivariate correlations were used to investigate the relationship between US acceptance of evolution and each variable.

Results: As predicted, there was a strong negative correlation between acceptance of evolution and religiosity and a strong positive relationship between acceptance and science degrees awarded, bachelor degree attainment, advanced degree attainment, average teacher salary, and GDP per capita.

Conclusion: Several implications for evolution education and acceptance are discussed.
\end{abstract}

\section{Background}

The importance of accepting and understanding the biological theory of evolution has been well documented (Gould 2002). Acceptance of evolution is essential for the advancement of medicine, agriculture, phenomena that are biological in nature, and other areas of science, such as geoscience (Dobzhansky 1973; Fail 2008; Gould 2002; Mayr 1982). Unfortunately, biological evolution is often perceived to be at conflict with a variety of variables including the worldviews associated with some religions (Heddy \& Nadelson, 2012; Rosengren et al. 2012).

Low levels of evolution understanding and acceptance may have a negative effect on scientific developments and support for science by society (Miller et al. 2006). For instance, acceptance of biological evolution may directly influence developments and understanding of the science associated with agriculture. Knowing that through artificial selection farmers can grow more and bigger crops faster, which leads to a larger profit, has the potential of feeding more people and is a domain of possible economic development. Further, acceptance of

\footnotetext{
* Correspondence: Heddy@usc.edu

'University of Southern California, 3470 Trousdale Parkway, Los Angeles, CA 90089, USA

Full list of author information is available at the end of the article
}

biological evolution is related to, and especially important to, medical advances and understanding diseases. Disease-causing bacteria and viruses can evolve into strains that are resistant to medication. It is imperative that patients, clinicians, and pharmacologists understand the potential evolutionary pathways for disease-causing microbes and the implications for treatments and pharmaceutical development. Finally, acceptance of evolution is important for scientists who test on animals. Certain animals are more genetically close to humans than others and, therefore, make better subjects for testing drugs, cosmetics, toxins, and other potentially harmful or beneficial substances. Knowledge of the distinct proximal and distal animal-human relationships can lead to the optimization of animal research to human benefit. Despite the many positive implications of accepting evolution, the US still remains low when compared on an international level (Heddy \& Nadelson, 2012; Miller et al. 2006).

Recently, researchers have explored the variables related to acceptance of evolution on a global level (Heddy \& Nadelson, 2012). For most countries, religiosity is negatively associated with evolution acceptance while school-life expectancy, science literacy, and GDP per capita are positively related to acceptance. However, the US was an outlier from the rest of the world, revealing 
relationships that were inconsistent with the general trend of the association between several variables related to public acceptance. That is, the US maintains a low level of acceptance of evolution and high school-life expectancy and GDP per capita.

The purpose of the present research was to explore the phenomenon of levels of acceptance of evolution in the US to further illuminate the explanation for the inverse relationship to school-life expectancy and GPD and to determine if state level phenomenon may be influencing national level data. Thus, we investigated how a range of variables are related to acceptance of evolution at the state level in the US. We explored the correlation between acceptance of evolution and religiosity, STEM degrees awarded, educational attainment, high school dropout rate, average teacher salary, and GDP per capita. Information for each variable was found for all 50 states. The results have many implications for the fields of science, education, and policy.

\section{Theoretical framework}

Much research has shown that many individuals have difficulty accepting the tenets of the theory of biological evolution (Alters and Alters 2001; Miller 2008). Acceptance of evolution may be influenced by many factors. Perhaps the most obvious explanation for the lack of acceptance is a perceived conflict between religious worldviews and evolution as the origin of species (Sinatra and Nadelson 2010; Rosengren et al. 2012). However, other variables may be at play as well, such as extent of education, access to education, access to informal science learning, and political associations. Thus, acceptance of evolution is likely to be associated with multiple factors.

In the exploration of evolution acceptance researchers have investigated variables related to acceptance at the individual level (Nadelson and Southerland 2010), with groups of individuals, such as science teachers (Rutledge and Mitchell 2002) and university education faculty (Nadelson and Sinatra 2009), and by country (Heddy \& Nadelson, 2012). Our investigation broadens this research by examining the variables related to acceptance of evolution in the US at the state level.

Internationally, public acceptance of evolution has been shown to be negatively related to religiosity and positively related to education level, GDP per capita and science literacy (Heddy \& Nadelson, 2012). In the present study, we explored these relationships to determine if they held true at the state level in the US. In general the populace of the US has a high level of religiosity, GDP per capita, and educational attainment as compared to many countries. As discussed previously, at the international level educational attainment and GDP per capita are positively related to acceptance of evolution (Heddy \& Nadelson, 2012). That is, as the level of education and the wealth of a population increase there is a corresponding increase in acceptance of biological evolution. However, the positive relationships between educational attainment, GDP per capita and evolution acceptance do not hold for the US. The lack of consistency in the predictors of evolution acceptance in the US compared with other countries led us to wonder if the relationships hold at the state level and if perhaps some states influenced US acceptance as a whole which would explain the anomaly.

\section{Evolution acceptance and religiosity}

Religiosity is defined as the extent to which people state that religion is very important to their lives (Pewforum. org 2010). Religious dogma has been shown to influence the way in which individuals perceive the world (Oser and Reich 1990). For example, previous research has shown a negative relationship between religiosity and acceptance of evolution (Heddy \& Nadelson, 2012; Alters and Alters 2001; Miller 2008; Nadelson and Sinatra 2009; Scott 2005). The negative association may be related to conflicting belief systems regarding the essence and origin of species. The US, in particular, has a high level of religiosity and low levels of evolution acceptance when compared on a global scale (Heddy \& Nadelson, 2012).

The US is geographically a large country with a very diverse populace. Due to this diversity we contend that it would be useful to report the relationship between religiosity and acceptance at the state level. Data at the state level allow for better control for population diversity. A comparison of religiosity by state or region in the US reveals segregated and diverse levels of religiosity. For this reason, we determined it was important to explore the relationship between religiosity and acceptance of evolution by state to gain a deeper insight into how different groups of people may be influencing our perceptions of US acceptance of evolution as a whole.

\section{Evolution acceptance and educational attainment}

We operationalized educational attainment through the following four categories: 1) attainment of high school diplomas, 2) completion of post-secondary bachelor degrees, 3) fulfillment of post-baccalaureate advanced degrees, and 4) high school dropout rate. Previous research indicates a positive relationship between level of education, college degree attainment, and acceptance of evolution (Heddy \& Nadelson, 2012; Nadelson and Sinatra 2009; Sustersic 2007). We hypothesized that as the number of years of education increase, personal science knowledge and/or reasoning abilities may increase which has been found to correspond with increased evolution acceptance (Nadelson and Southerland 2010). Further, there is evidence that shows that evolution acceptance among undergraduate 
students increases regardless of academic major (Nadelson and Sinatra 2009; Sustersic 2007).

The positive relationship between educational attainment and evolution acceptance is true for many countries excluding the US (Heddy \& Nadelson, 2012). The US stands out as an anomaly as the populace of the US is comparatively highly educated while holding a relatively low level of evolution acceptance (Heddy \& Nadelson, 2012; Miller et al. 2006). The inconsistency of the US with other developed nations in terms of the relationship between educational attainment and evolution acceptance merits additional investigation and data collection. The additional research should provide the data needed to explain this phenomenon empirically. We predicted that those states with higher levels of educational attainment and lower dropout rates would have higher levels of evolution acceptance.

\section{Evolution acceptance and science degrees awarded}

Previously conducted research has revealed a positive correlation between science literacy and acceptance of evolution (Nadelson and Southerland 2010). We reasoned that there is a positive relatively strong relationship between science literacy and attainment of a postsecondary science degree. Therefore, we predicted that we would find higher levels of public acceptance of evolution in states where a greater percentage of STEM related degrees are awarded. Further, understanding and acceptance are essential to those working in science, technology, and engineering as they seek to develop (biological) solutions while minimizing influences on the environment (e.g., radiation leading to mutations and antibiotic resistant bacteria) that may impact species viability - including humans.

Recently, many states have been developing policies intended to increase the number of STEM degree and career seekers, particularly within their states. Currently, it is predicted that over the next ten years there will be $17 \%$ growth in STEM-related jobs compared to $10 \%$ in non-STEM-related jobs and more than two thirds of those will require a bachelor level degree (Carnevale et al. 2011). Acceptance of biological evolution may be one proxy for the potential for states to meet their policy objectives related to the development of STEM professionals. Further, acceptance may also be an indicator of the possibility of meeting the future needs for STEM professionals. Thus, our exploration of the relationship between STEM degree attainment and evolution acceptance by state provides a possible indicator of the potential success of STEM education initiatives.

\section{Evolution acceptance and teacher salary}

We thought it would be interesting to consider the relationship between public acceptance of evolution and average teacher salary, as the association may have important implications for science instruction. Teaching biological evolution requires deep knowledge of a wide range of biological and societal issues (Rosengren et al. 2012). The acquisition of a deep knowledge of biological evolution likely requires ongoing engagement in education, which in many cases is motivated by the associated salary increases (Scribner 1999). Thus, higher teacher salaries may reflect greater engagement in professional development. Further, higher salaries are an incentive for teachers to remain in the classroom (Allen 2005). Based on these reports we posit that higher salaries are likely to reflect a more educated and experienced teaching workforce, which is likely to be better prepared to teach evolution effectively. Exploration of the relationship between teacher salary levels and biological evolution may clarify the situation while illuminating others, such as the value that a state places on education. We realize that other factors, such as years of service and level of education, may impact teacher salary; however, we anticipated the variations in teacher salary due to these other factors would be consistent across states. Therefore, the average teacher salaries are reflective of the support for K-12 education within a state more than other variables or influences.

\section{Evolution acceptance and GDP per capita}

Gross domestic product (GDP) per capita may act as both a proxy and as an influence on the world view of a populace. We posit that the populace in countries with low GDPs, with limited economic and industrial development, have limited access to formal and informal science education and opportunities to engage in learning about the scientific perspective of biological evolution (Jaumotte et al. 2008). The relationship between evolution acceptance and GDP per capita was found to be the case when considered on an international scale (Heddy \& Nadelson, 2012). Once again, the US appears to be an anomaly. The US is one of the most advanced countries in the world with a comparatively high GDP per capita. Despite its apparent superior GDP per capita, the US maintains a relatively low level of public acceptance of evolution. However, the country level data may not be particularly useful when exploring different regions of the US due to uneven wealth distribution.

The wealth distribution in the US is known to differ greatly between the rich and the poor, and these disparities have been increasing over the last 40 years (Domhoff 2012). Although the US holds the largest portion of the world's wealth, it belongs to a small percentage of citizens. For this reason, we posit that populace in states with lower GDP have minimal wealth and an associated more limited access to educational 
opportunities. Reduced education-related resources are likely to have a negative impact on learning and, specifically, science education which influences knowledge and acceptance of evolution. However, the relationship between state GDP and evolution acceptance has not been documented before which provides justification for exploring this relationship.

\section{Research question}

Based on our investigation of the literature and knowledge regarding public acceptance of evolution we generated the following questions to guide our research:

- What is the relationship between public acceptance of evolution and religiosity at the state level in the US?

- What is the relationship between educational attainment and public acceptance of evolution at the state level in the US?

- What is the relationship between public acceptance of evolution and percentage of STEM degrees conferred among all degrees in a state in the US?

- What is the relationship between average teacher salary and public acceptance of evolution by state in the US?

- What is the relationship between public acceptance of evolution and GDP per capita by state in the US?

We predicted that there would be a negative relationship between public acceptance of evolution and religiosity as well as acceptance and high school dropout rate. We also predicted that there would be positive relationships between public acceptance of evolution and all forms of diploma or degree attainment, percentage of STEM degrees conferred, average teacher salary and GDP per capita.

\section{Methods}

Sample

Our study included data from all 50 states in the US. We recovered data for all variables investigated from extant data. Data collection sources and methods are discussed below.

\section{Data collection \\ Evolution acceptance}

We conducted secondary data analysis by gaining access to extant data on public acceptance of evolution by state in the US religious landscape survey (Pewforum.org 2010). Pewforum.org 2010 delivered a questionnaire to citizens in each state who were asked to respond, completely agree, mostly agree, mostly disagree, or completely disagree to the following statement: Evolution is the best explanation for the origins of human life on earth. We examined the percentage of participants who responded 'completely agree' to the statement (see Figure 1). State sample size was relative to overall population size for each state. For example, California had 3,574 participants, while Idaho had 196.

The religious landscape survey was conducted in two parts (Pewforum.org 2010). The first part was conducted in 2007 in which 35,556 citizens in the continental US were polled regarding their religious habits, beliefs, and commitment. The second part of the survey was conducted in 2008 in which a representative sample of citizens from Hawaii and Alaska were included. The survey was conducted through phone interviews, which implemented a list-assisted random digit-dialing sample.

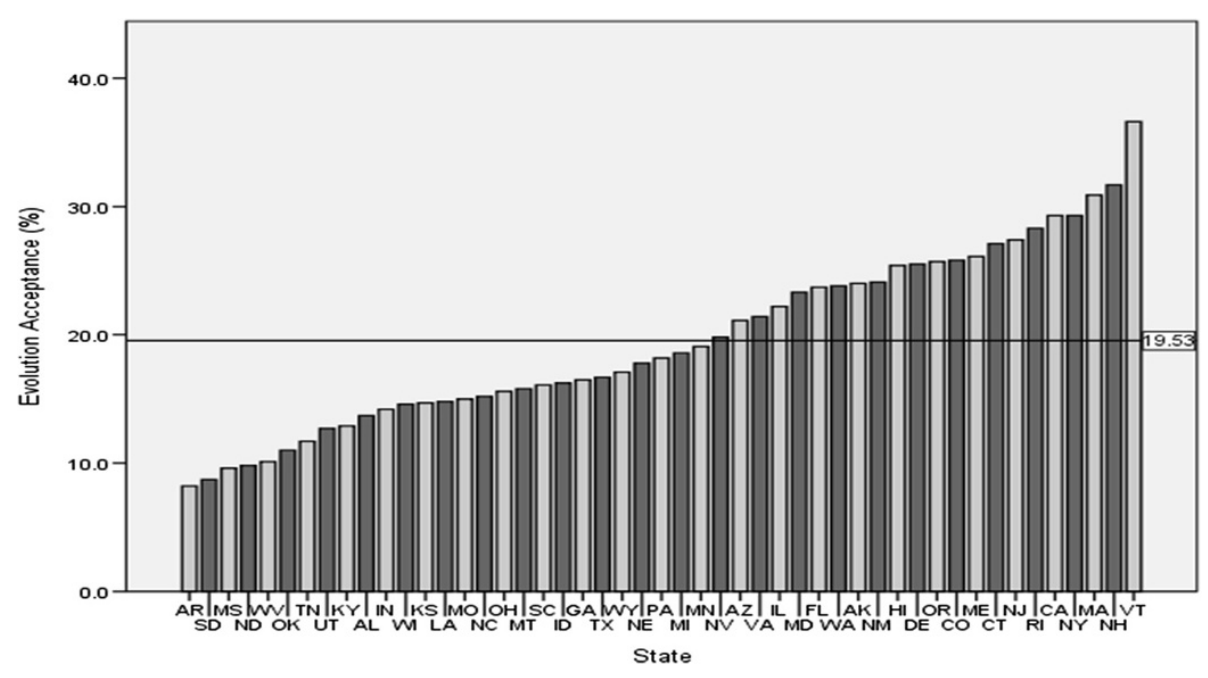

Figure 1 Evolution acceptance by state: national average is $19.53 \%$. 


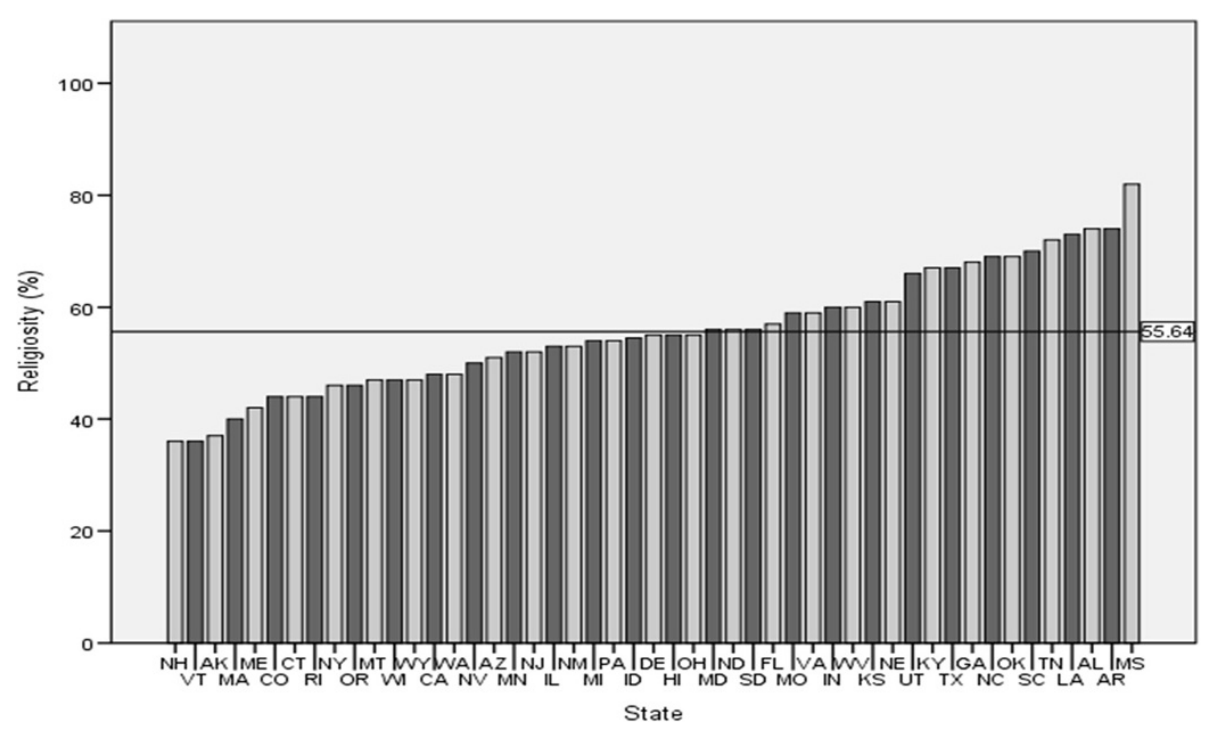

Figure 2 Religiosity by state: national average is $55.64 \%$.

Additional non-random interviews were conducted with low-incidence populations such as Hindu, Bhuddist and Orthodox Christians. The sample demographics were balanced to match population parameters for sex, age, education, race, Hispanic origin, region, country of birth, and population density. Finally, outliers were removed to prevent individual interviews from having too much influence on the final results. The research is reported with a .06 margin of error. Pewform.org is not responsible for the present analysis or interpretation.

\section{Religiosity}

We collected scores for religiosity from the (Pewforum. org 2010) US religious landscape survey. Participants were asked to respond, very important, somewhat important, not too important, not at all important, or refuse to answer to the question: How important is religion in your life? Pewforum.org combined states that had a low sample but similar geography and demography including North/South Dakota, Montana/Wyoming, Connecticut/Rhode Island, and New Hampshire/Vermont. For the states that were paired we assigned each state the score that was assigned to the grouping. We examined the percentage of citizens who responded that religion was very important in their life (see Figure 2).

\section{Educational attainment, STEM degrees awarded and average teacher salary}

Data for diploma and degree attainment, STEM degrees awarded and average teacher salary were extracted from

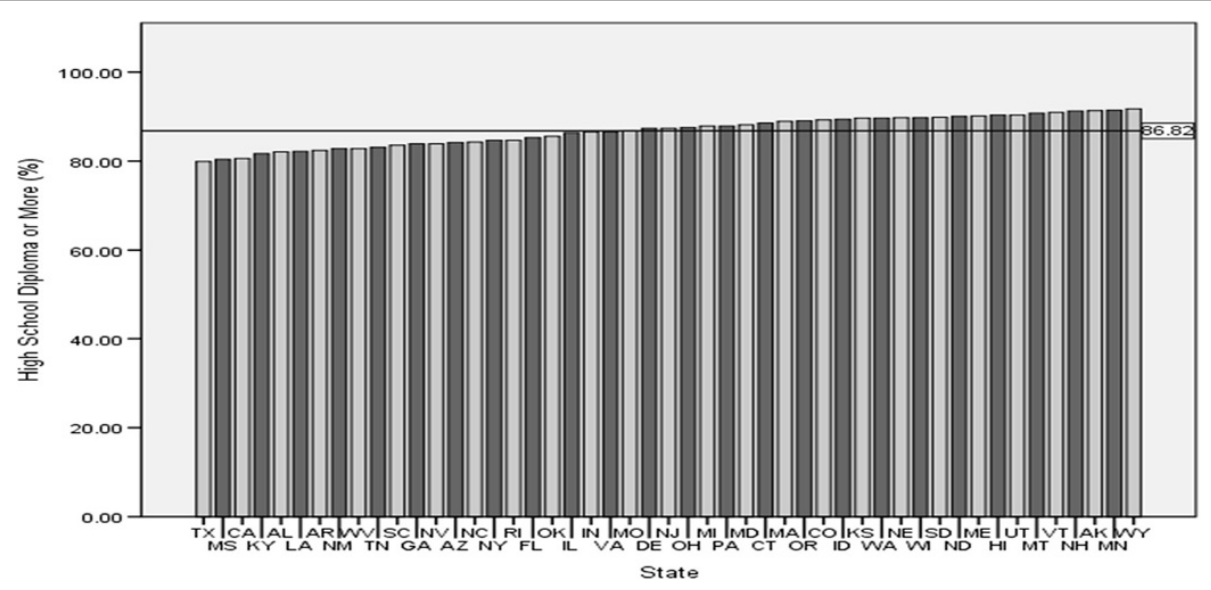

Figure 3 High school diploma attainment by state; national average is $86.82 \%$. 


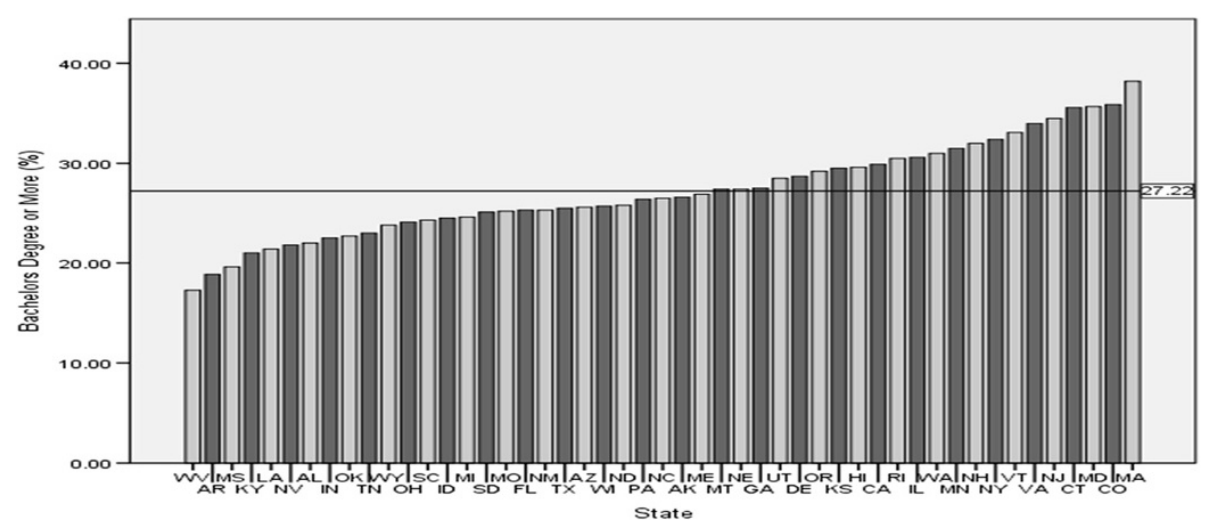

Figure 4 Bachelor degree attainment by state: national average is $27.22 \%$.

extant data available from United States Census Bureau (2011). We extracted educational attainment on three levels. The first level was the reported percentage of citizens in a given state with a high school diploma or equivalent (see Figure 3). The second level was the percentage of state citizens with a bachelor degree or higher (see Figure 4). We used the same approach to extract data for advanced degree or higher (see Figure 5). We extracted STEM degrees as the reported percentage of science and engineering degrees that were awarded among all degrees (see Figure 6). We extracted average teacher salary for the reported amounts in US dollars (see Figure 7).

\section{High school dropout rate}

Data for high school dropout rate was recovered from the Alliance for Excellent Education (All4ed.org, 2012). All4ed.org provides a statistical snapshot of high schools for each state in the nation. Information is provided for economic information, high school and college graduation rates and states advancement in developing a longitudinal data system. High school dropout rate is presented as the percentage of students in a given state not graduating (see Figure 8). It is important to note that the calculations for high school diploma attainment and school dropout are independent and, therefore, the values and rankings are likely to be different with some trending overlap.

\section{GDP per capita}

We secured data for state GDP per capita from the United States Department of Commerce, Bureau of Economic Analysis 2011. State GDP per capita was reported in US dollars based on the recognized goods and services produced within a given state in a given time period (usually within a 12-month period). GDP per capita is an indicator of the standard of living in a state (see Figure 9).

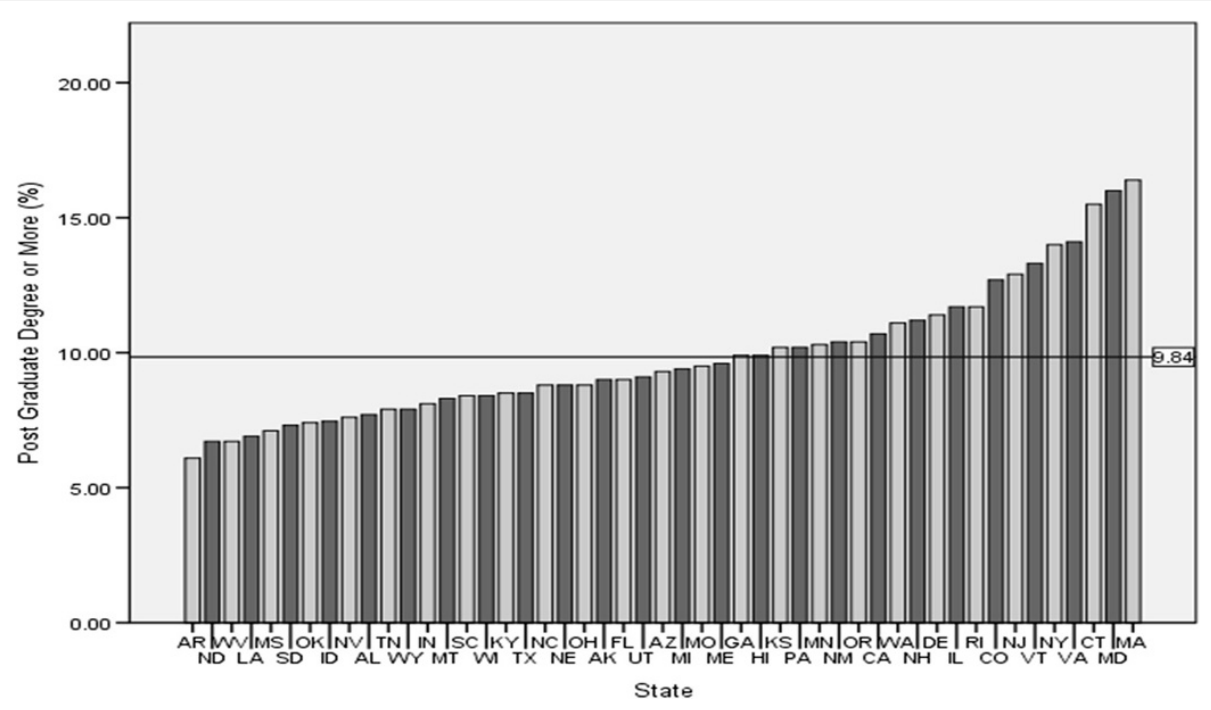

Figure 5 Post graduate degree attainment by state: national average is $9.84 \%$. 


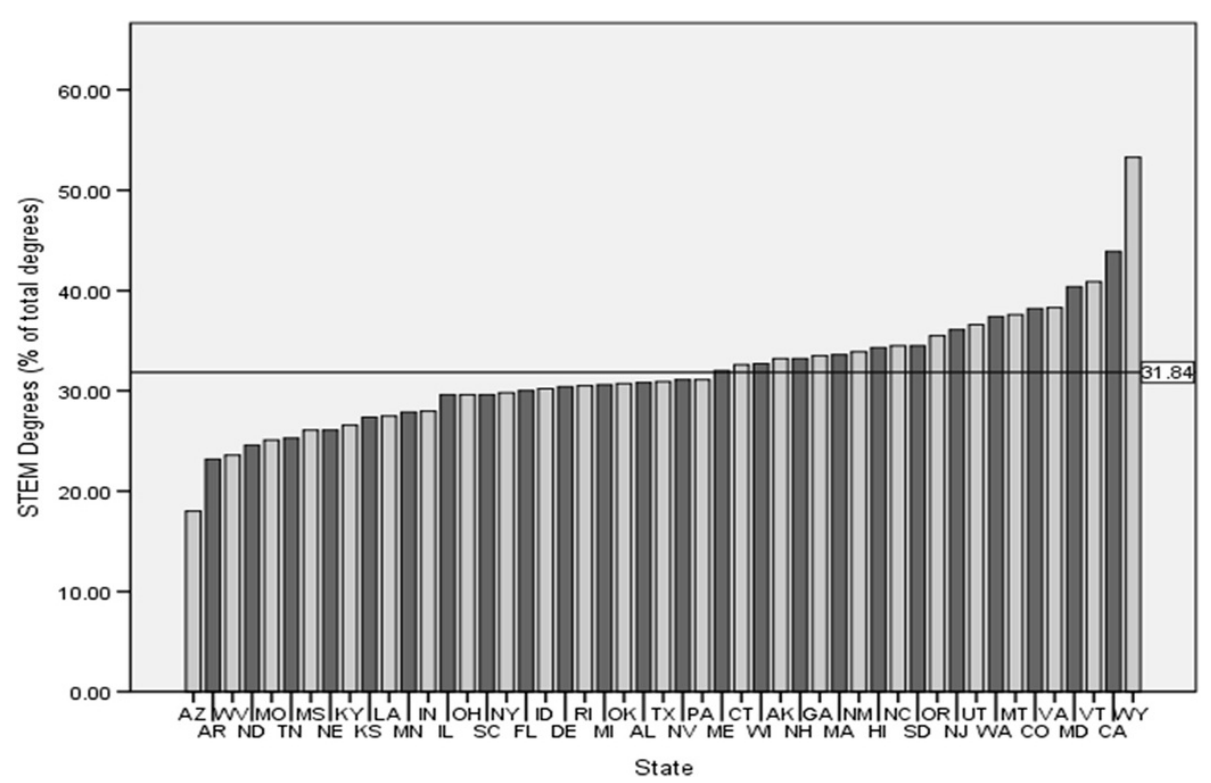

Figure 6 STEM degree attainment (\% of total degrees) by state: national average is $31.84 \%$.

\section{Data set development and analysis}

In our analysis we included public acceptance of evolution, religiosity, our four measures of educational attainment by percentage of each state sampled, STEM degrees as the percentage of science or engineering degrees compared to the total number of degrees granted. We included average teacher salary and GDP per capita in US dollars. Before we engaged in our analysis, we examined our state level data for consistency in number of responses relative to the full population of the state.

We began our analysis with an examination of the relationships between the variables by calculating the correlations. We then calculated the linear relationships for each of the variables with respect to evolution acceptance. We concluded with a regression analysis to determine which of our independent variables combine significantly to describe state level acceptance of biological evolution. We were striving for parsimony in our effort to create an equation that could be effectively used to predict acceptance of evolution and explain the greatest level of variance in acceptance using the fewest number of variables.

\section{Results}

Correlations between variables

Our bivariate correlation calculations are presented in Table 1. Of particular interest to our research were the correlations with acceptance of evolution. Our analysis

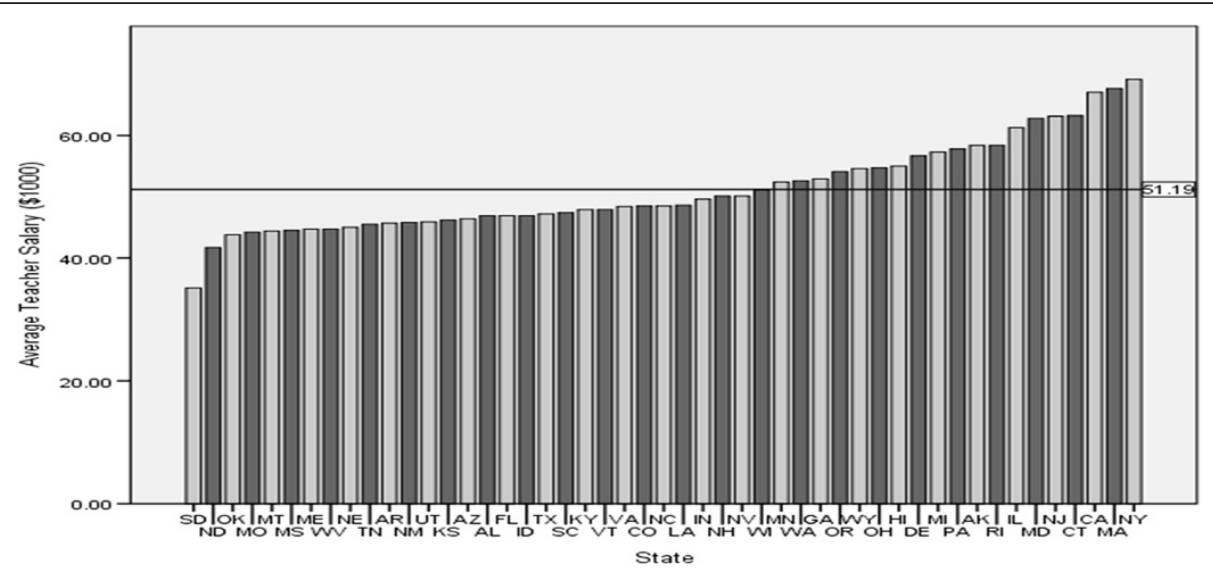

Figure 7 Average teacher salary by state: national average is $\$ 51,190$ or $(51.19 * \$ 1000)$. 


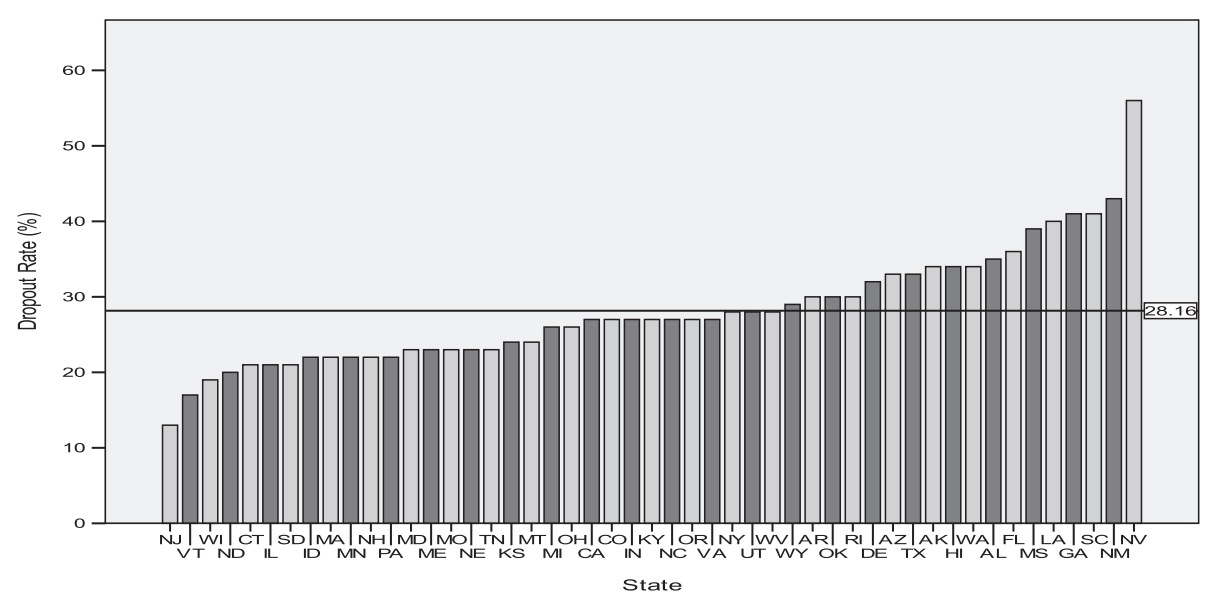

Figure 8 High School dropout rate by state: national average is $28.16 \%$.

revealed that with the exception of high school diploma and dropout rate all variables were significantly correlated with evolution acceptance. In addition, our analysis revealed that most other variables were significantly correlated.

We acknowledge that there may be some level of covariance of variables in our study, particularly those associated with acceptance of evolution. However, the largest coefficient of determination among these variables was that of post-graduate advanced degree attainment and teacher salary, $\mathrm{r}^{2}=.47$. The correlation suggests that about $47 \%$ of the variation in teacher salary (at the state level) can be explained by advanced degree attainment (again at the state level), which suggests states with higher teacher salaries have a populace with a greater level of advanced degree attainment. Yet, $53 \%$ of the variance in teacher salary or advanced degree attainment is associated with other variables. Thus, even with the largest correlation, more than $50 \%$ of the variation is due to other variables. The correlations represent the irreducible nature of these data.
Therefore, we recognize that there is some covariance in these data, but that there is also a unique contribution of each variable related to public acceptance of evolution.

\section{Evolution acceptance and religiosity}

Our first question asked was, 'What is the relationship between public acceptance of evolution and religiosity at the state level in the US?' To answer this question we examined the bivariate correlation between religiosity and public acceptance of evolution. Consistent with other studies (Heddy \& Nadelson, 2012; Alters and Alters 2001; Miller 2008; Nadelson and Sinatra 2009; Scott 2005), our analysis revealed a strong negative correlation between religiosity and public acceptance of evolution, $\mathrm{r}=-.76$, $P<.0005$ (see Figure 10). The results suggest that the higher a state's citizens religiosity, the lower their acceptance of evolution.

Our linear analysis revealed a significant slope of -.47 $(t=-7.98, P<.01)$ and an intercept of $45.85(t=13.62$, $P<.01)$. Interpreted, these outcomes indicate that for

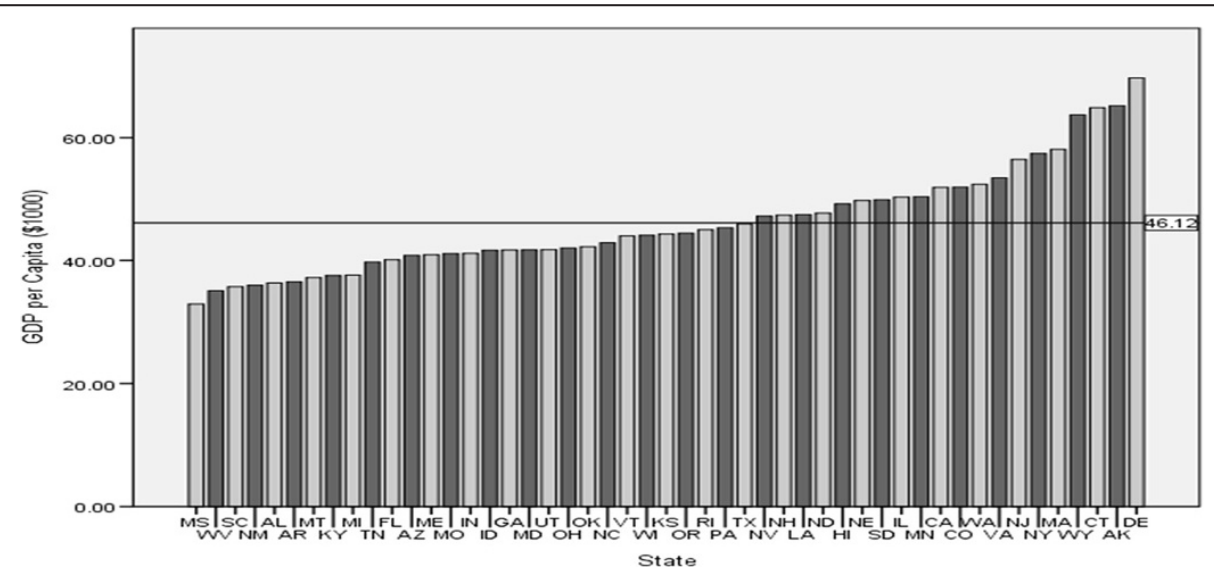

Figure 9 GDP per Capita by State: national average is $\$ 46,120$ or $\left(46.12^{*} \$ 1000\right)$. 
Table 1 Correlation of all variables

\begin{tabular}{|c|c|c|c|c|c|c|c|c|c|}
\hline & $\begin{array}{c}\text { Evolution } \\
\text { acceptance }\end{array}$ & Religiosity & $\begin{array}{l}\text { High school } \\
\text { diploma }\end{array}$ & $\begin{array}{c}\text { Bachelor } \\
\text { degree }\end{array}$ & $\begin{array}{c}\text { Advanced } \\
\text { degree }\end{array}$ & $\begin{array}{l}\text { Science } \\
\text { degree }\end{array}$ & $\begin{array}{l}\text { Dropout } \\
\text { rate }\end{array}$ & $\begin{array}{c}\text { Teacher } \\
\text { salary }\end{array}$ & $\begin{array}{c}\text { GDP per } \\
\text { capita }\end{array}$ \\
\hline Evolution Acceptance & - & $-.76^{* *}$ & .26 & $.76^{* *}$ & $.78^{* *}$ & $.42^{* *}$ & -.12 & $.63^{* *}$ & $.47^{* *}$ \\
\hline Religiosity & & - & $-.63^{* *}$ & $-.61^{* *}$ & $-.53 * *$ & $-.41^{* *}$ & $.33^{*}$ & $-.44^{* *}$ & $-.51^{* *}$ \\
\hline High School Diploma & & & - & $.57^{* *}$ & $.63^{* *}$ & $.35^{*}$ & $-.52^{* *}$ & .05 & $.41^{* *}$ \\
\hline Bachelor Degree & & & & - & $.58^{* *}$ & $.46^{* *}$ & $-.41^{* *}$ & $.58^{* *}$ & $.60^{* *}$ \\
\hline Post-Graduate Degree & & & & & - & $.38^{* *}$ & $-.30^{*}$ & $.69^{* *}$ & $.54^{*}$ \\
\hline Science Degree & & & & & & - & -.10 & $.33^{*}$ & $.43^{* *}$ \\
\hline Dropout Rate & & & & & & & - & -.13 & -.18 \\
\hline Teacher Salary & & & & & & & & - & $.59^{* *}$ \\
\hline GDP per Capita & & & & & & & & & - \\
\hline
\end{tabular}

* Correlation is significant at $.05{ }^{* *}$. Correlation is significant at .01 or higher.

every one percent increase in religiosity, acceptance of evolution decreases about half of a percent. Further, given our data and the predicted linear relationship, a state with zero percent religiosity would have an acceptance level of almost $46 \%$ (which is an extrapolation because no state has zero percent religiosity).

\section{Acceptance and educational attainment}

Our second research question asked, 'What is the relationship between educational attainment and public acceptance of evolution at the state level in the US?' To answer this question, we examined the bivariate correlation between high school diploma attainment, bachelor degree attainment, advanced degree attainment, high school dropout rate and public acceptance of evolution. Our results show a non-significant correlation between evolution acceptance and high school diploma attainment, $\mathrm{r}=.26$, a non- significant relationship with high school dropout rate, $\mathrm{r}=-.12$, a high positive relationship with bachelor degree attainment, $r=.76$, $P<.0005$ (see Figure 11), and a strong positive correlation with advanced degree attainment, $\mathrm{r}=.78, P<.0005$ (see Figure 12). Interpreted, our results suggest that there is no difference between high school graduates or high school dropouts by state with regard to evolution. However, the more advanced degree a citizen attains the more likely that person is to accept evolution.

Our linear analysis revealed a slope of $1.09(t=-7.98$, $P<.01)$ and an intercept of $-10.03(t=-2.68, P<.01)$. Interpreted, these outcomes indicate that for every percentage increase in a state's bachelor degrees or more there is about a one percent increase in evolution acceptance. The extrapolation suggests that if a state populace has no bachelor degrees then the acceptance of

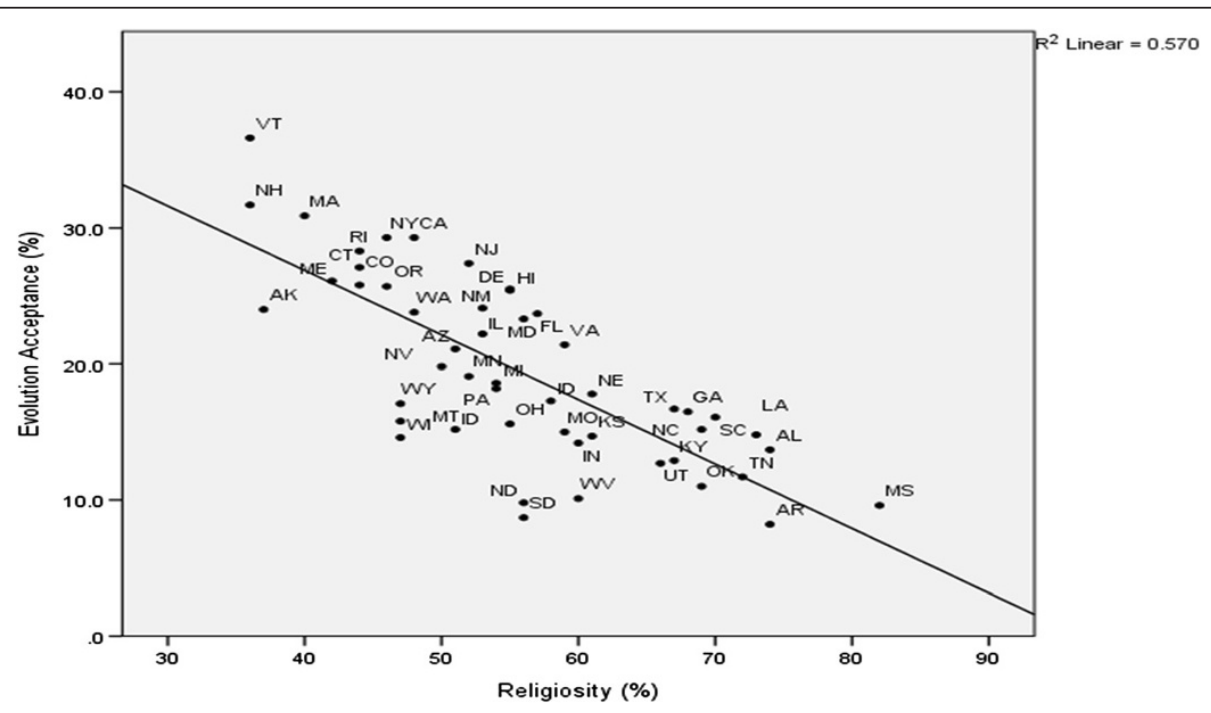

Figure 10 Evolution acceptance and religiosity scatter plot, $\mathrm{r}^{2}=.57$. 


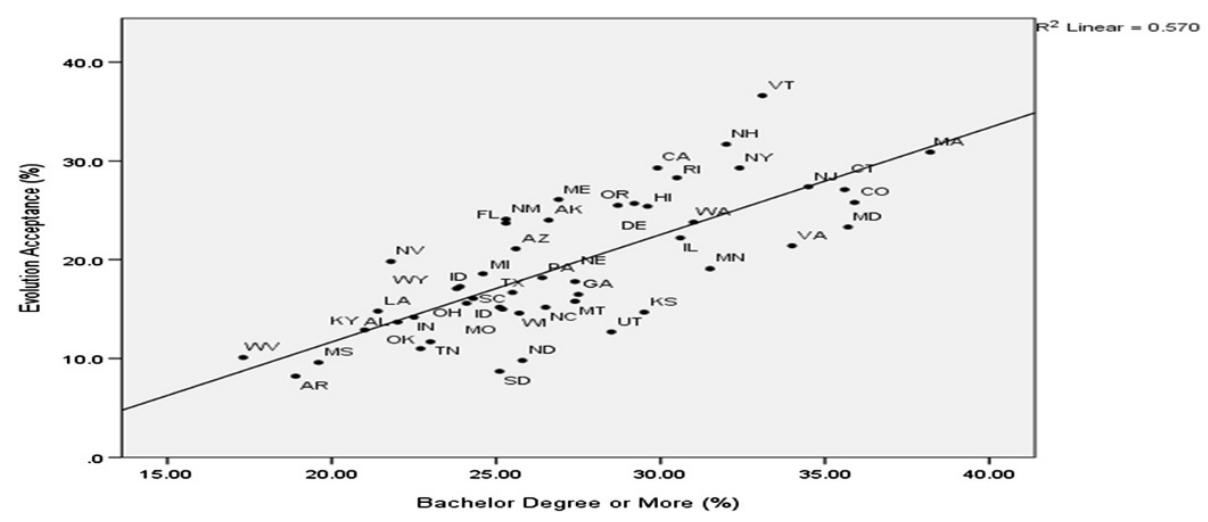

Figure 11 Evolution acceptance and bachelor degree scatter plot, $r^{2}=.57$.

evolution would be -10.03 . A more meaningful interpretation of the data would be for the states in which acceptance is zero, the percentage of bachelor degrees would be about $9.23 \%$. The extrapolation is a situation that does not exist in our data because no states had a zero level of evolution acceptance.

Our linear analysis revealed a slope of $2.12(t=8.50$, $P<.01)$ and an intercept of $-1.32(t=-.53, P>.05)$. Interpreted, these outcomes indicate that for every one percent increase in advanced or graduate degrees in a state, the evolution acceptance in the state increases about two percent. Further, if extrapolated to where the number of advanced degrees is zero then the acceptance would be zero.

\section{Evolution acceptance and STEM degrees awarded}

Our third question asked, "What is the relationship between public acceptance of evolution and percentage of STEM degrees conferred among all degrees in a state in the US?' To answer this question we examined the bivariate correlation between STEM degrees awarded and public acceptance of evolution. The analysis exhibits a strong positive correlation between percent of STEM degrees awarded and evolution acceptance, $\mathrm{r}=.42$, $P=.0005$ (see Figure 13). Our results show that the higher a state's percentage of STEM degrees attained the higher its evolution acceptance.

Our linear analysis revealed a slope of $.49(t=3.21$, $P<.01)$ and an intercept of $3.90(t=.79, P>.05)$. Interpreted, these outcomes indicate that for every one percent increase in the number of STEM degrees awarded in a state there is about a half a percent increase in the level of evolution acceptance. Given the non-significant intercept, the extrapolation of our data indicates that a state with zero percent STEM degrees awarded would have a level of zero acceptance of evolution.

\section{Acceptance and teacher salary}

Our fourth research question asked, 'What is the relationship between average teacher salary and public acceptance of evolution by state in the US?' To answer this question, we examined the bivariate correlation between average teacher salary and public acceptance of evolution. Our analysis revealed a strong positive correlation between teacher salary and acceptance, $\mathrm{r}=.63, P<.0005$ (see Figure 14). The findings indicate that the higher a

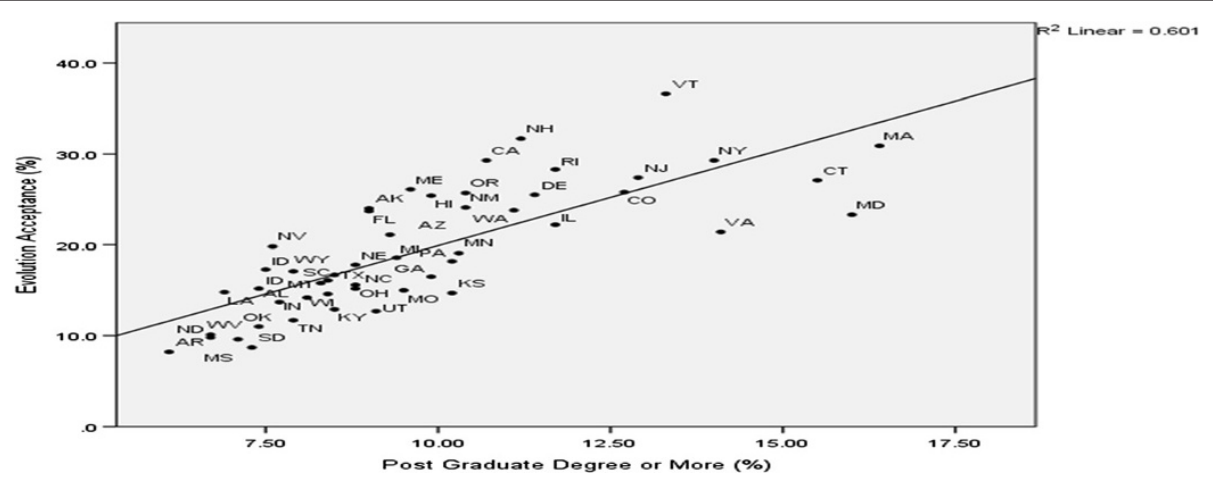

Figure 12 Evolution acceptance and post graduate degree scatter plot, $\mathrm{r}^{2}=.60$. 


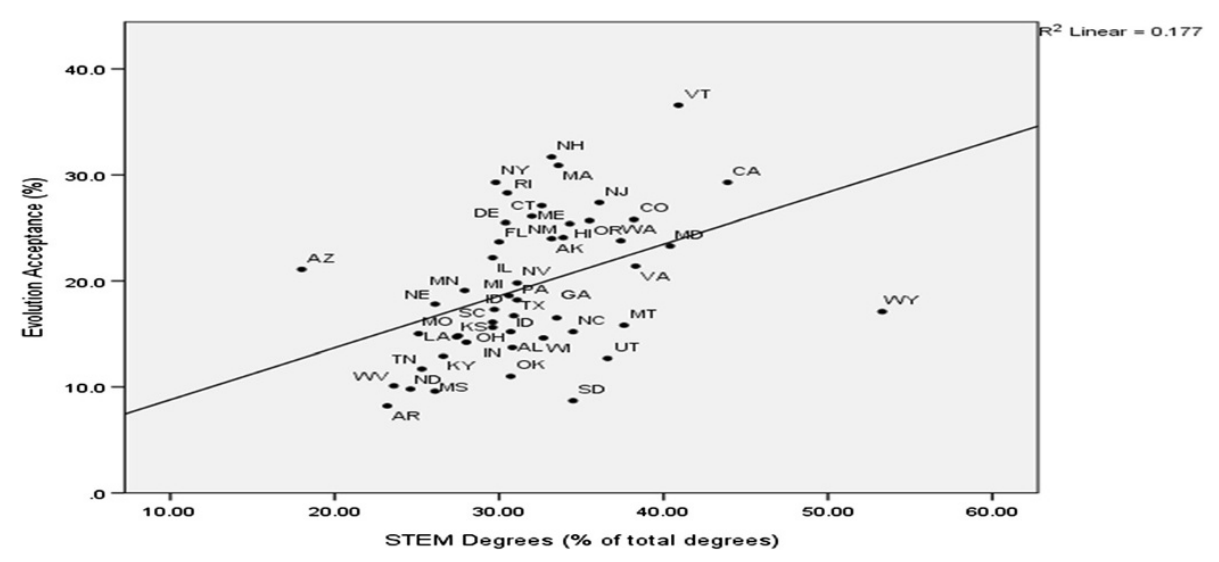

Figure 13 Evolution acceptance and STEM degree scatter plot, $\mathrm{r}^{2}=.18$.

state's average teacher salary, the higher its public acceptance of evolution.

Our linear analysis revealed a slope of $.59(t=5.63$, $P<.01)$ and an intercept of $-10.45(t=-1.95, P>.05)$. Interpreted, these outcomes indicate that for every $\$ 1,000$ increase in teacher salaries there is a corresponding increase in evolution acceptance of about six tenths of a percent. Again, the non-significant intercept extrapolated from the data suggests that if the salary was zero then acceptance would be zero.

\section{Acceptance and GDP per capita}

Our fifth question asked, 'What is the relationship between public acceptance of evolution and GDP per capitaby state in the US?' To answer this question, we examined the bivariate correlation between GDP per capita and public acceptance of evolution. Our results exhibit a strong correlation between GDP per capita and acceptance, $\mathrm{r}=.47, \quad P<.0005$ (see Figure 15). The findings suggest that the higher a state's GDP per capita, the its their public acceptance of evolution.

Our linear analysis revealed a slope of $.38(t=3.73$, $P<.01)$ and an intercept of $2.05(t=.43, P>.05)$. Interpreted, these outcomes indicate that for every about $\$ 1,000$ increase in GDP per capita in a state the populace experiences about four tenths of an increase in evolution acceptance. As reported previously, the extrapolated line with the non-significant intercept suggests that if GDP per capita was zero then a state would report a zero acceptance in evolution.

\section{Composite data analysis}

To determine the overall influence of each of our independent variables on acceptance (dependent variable), we conducted a regression analysis. We added variables to the analysis as depicted in Table 2 . Our goal was parsimony to create the simplest model to explain the greatest level of evolution acceptance variance. Our analysis

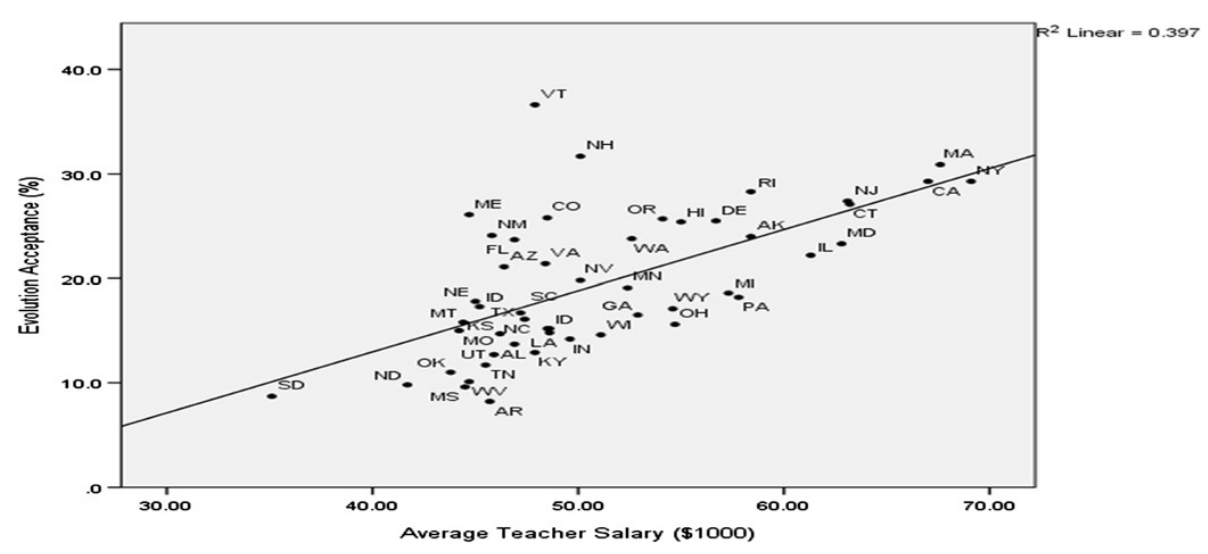

Figure 14 Evolution acceptance and average teacher salary scatter plot, $r^{2}=.40$. 


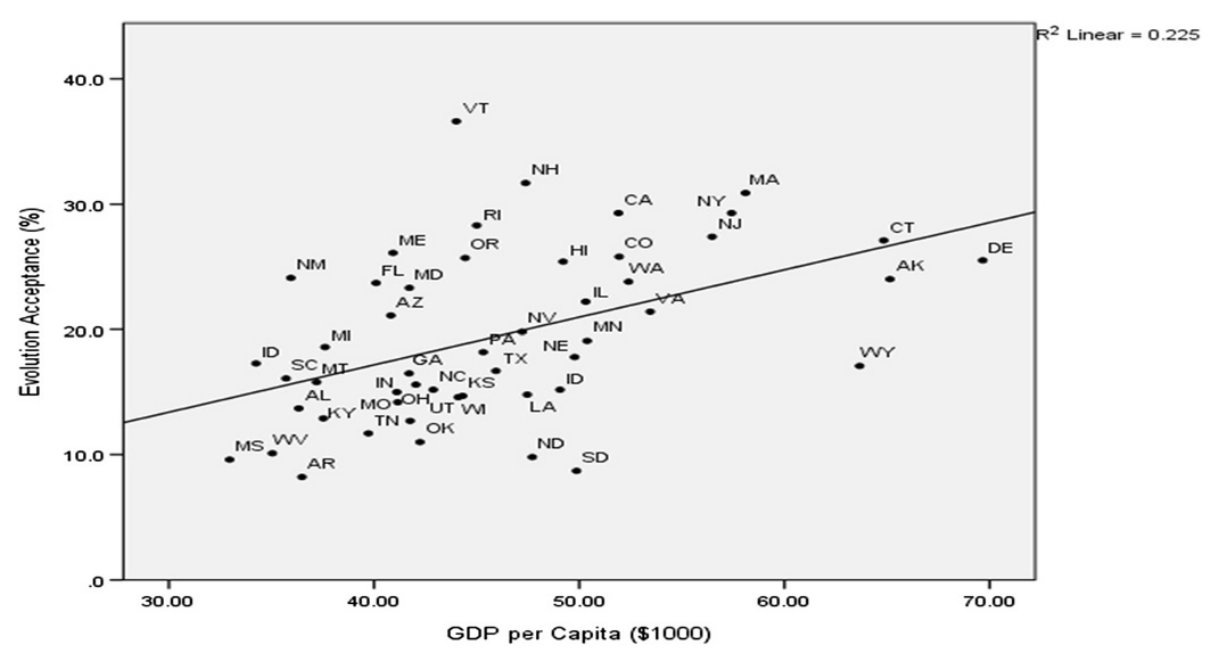

Figure 15 Evolution acceptance and GDP per capita scatter plot, $r^{2}=.23$.

revealed that four independent variables significantly contributed to the regression model, and combined explained $83 \%$ of the variance in evolution acceptance (see Table 2).

The model that resulted from our regression was:

$$
\begin{aligned}
\text { Evo Accept }= & .43(\text { Religiosity })-.69(\text { highschoolgrad }) \\
& +.82(\text { bachelors })+.14(\text { dropoutrate }) \\
& +77.12
\end{aligned}
$$

When combined, four of our seven variables associated with evolution acceptance significantly contribute to explain the variance in evolution acceptance. Thus, we found that evolution acceptance is most completely predicted by our measures of religiosity, percentage of bachelor degrees, percentage of high school graduates, and dropout rates.

\section{Discussion and implications}

The US is an outlier with regard to the low levels of public acceptance of evolution when juxtaposed to other nations with comparable GDP per capita and educational attainment (Heddy \& Nadelson, 2012). Interestingly, we found similar trends in our comparison of these variables across states within the US as those found internationally. For instance, as exhibited in previous research, religiosity correlated highly with evolution acceptance which we attribute to a likely personal conflict between a faith based explanation and the scientific explanation for the origin of species (Alters and Alters 2001; Miller 2008; Nadelson and Sinatra 2009; Scott 2005).

The positive correlation between educational attainment and evolution acceptance that we found at the state level is consistent with findings from international data (Heddy \& Nadelson, 2012). It appears that as the educational level increases individuals are more likely to accept evolution, a trend that has been empirically documented at the country level (Heddy \& Nadelson, 2012), individual level (Nadelson and Sinatra 2009; Sustersic 2007), and now at the state level. The association between educational attainment and evolution acceptance suggests that additional engagement in education by the populace is fundamental to elevating levels of evolution acceptance.

Our finding of a positive correlation between STEM degree attainment and acceptance suggests that learners' engagement in STEM, in general, is sufficient to elevate levels of evolution acceptance. However, it may be that

\begin{tabular}{|c|c|c|c|c|c|}
\hline \multirow{2}{*}{ Model } & \multirow{2}{*}{$\mathbf{R}$} & \multirow{2}{*}{$\mathrm{R}^{2}$} & \multicolumn{3}{|c|}{ Change statistics } \\
\hline & & & $\mathrm{R}^{2}$ Change & F Change & Sig. F Change \\
\hline Religiosity & .76 & .57 & .57 & 63.74 & .00 \\
\hline Religiosity, highschoolgraduate & .80 & .64 & .07 & 9.49 & .00 \\
\hline Religiosity, highschoolgraduate, bachelors & .90 & .82 & .17 & 43.63 & .00 \\
\hline Religiosity, highschoolgraduate, bachelors, dropoutrate & .91 & .83 & .02 & 4.62 & .04 \\
\hline
\end{tabular}
students who seek STEM degrees may be more likely to

Table 2 Stepwise addition of variables 
accept evolution. Regardless, our findings suggest that acceptance of evolution may result from the domain general focus on STEM, rather than the domain specific focus on biological science. Our finding has important ramifications for STEM-based developments that are associated with biological evolution. Based on our finding we argue that increasing the number of people with deep knowledge in STEM will lead to greater acceptance of biological evolution, which provides an additional justification for increasing the attainment of STEM degrees. The association between evolution and many scientific and technological innovations suggests that deeper knowledge of STEM may be an effective way to address engagement at the societal level as well as research and development.

The relationship between STEM degrees and evolution acceptance suggests that the acceptance of evolution may be a contributing factor influencing the pursuit of a STEM degree and career. Thus, given the current need for STEM degrees (Tyson et al. 2007) and the possibility that students may avoid biologically founded STEM careers there may be a need to develop interventions to relieve the perceived conflict between religious worldviews and acceptance of evolution as a means of addressing the STEM employee shortage. Regardless, the relationship between acceptance, religiosity, and STEM degree attainment certainly warrants further research.

The positive correlation between evolution acceptance and average teacher salary is intriguing. We posit that states with low acceptance of evolution may spend less time on task with science because teachers in those states have limited capacity for teaching science. It may be that the science instructors in low acceptance states do not have a proper preparation in teaching biological evolution, leading to low levels of acceptance by their students. If this is the case, interventions need to be implemented to increase science instructors' knowledge of biological evolution, perhaps using the incentive of salary to increase the retention of highly capable teachers and to engage more teachers in professional development in evolution education. Although our data are correlational and do not suggest causal explanations, the potential of professional development in evolution education for increasing evolution knowledge and acceptance is worth further investigation.

There was a high positive correlation between evolution acceptance and state GDP per capita. The US is an outlier with regards to acceptance and GDP per capita internationally (Heddy \& Nadelson, 2012). However, the results show a similar pattern when acceptance and GDP per capita are explored by state. Whether comparing countries or states, GDP per capita is positively associated with acceptance. The positive correlation may reflect that living conditions in many US states limit access to education (both formal and informal) and constrain engagement in further learning for pleasure. Thus, we hypothesize that lower socioeconomic status (SES) citizens may not have the resources, opportunity, or motivation to engage in learning about biological evolution leading to low acceptance.

\section{Limitations}

There are two major potential limitations to our study. The first limitation is related to the nature of the data sets that we analyzed. When using secondary data analysis assumptions about the quality, consistency, and methods used to gather the data are often made. To our knowledge, the data used to conduct our analysis were the best available for the variables we assessed. We argue that our results should be used as preliminary data to explore related research questions in more depth using primary data.

The nature of our analysis and the interpretation of results is the second limitation of our study. We did not collect the initial data used in this study and, therefore, relating it to acceptance of evolution may not be what was intended by the original researchers. Although we researched data collection methodology of all the variables, we had to make an assumption that the data could be interpreted regardless of the context in which it was collected. Further inquiry into the validity of such analysis and interpretations is warranted.

The third limitation is the nature of our data. Although we did not have any coefficients of determination over .48 , our data were correlated to some extent. The correlations influenced how data were used and interpreted in our analysis. However, because of the unique variance explained by the data, we determined that each of our variables provided a unique contribution to the analysis and subsequent relationship to evolution acceptance. We do not imagine it would be possible to examine any of these data without consideration of the correlation. It is certainly worthwhile to seek state level variables that could be used to predict evolution acceptance and that are not correlated.

\section{Conclusions}

The goal of our research was to explore the relationship between variables related to public acceptance of evolution at the state level for the US. We sought to investigate if religiosity, educational attainment, and GDP per capita were correlated similarly to the country as a whole. We found that the correlations by state were more similar to those shown internationally (Heddy \& Nadelson, 2012). The US is an extremely diverse country with regard to ethnicity, SES, and religious affiliation and, thus, national data obscures some of this variation. Further, the variables in this study may be useful to 
predict evolution acceptance in given states. The present study raises many important questions to be explored in future research.

\section{Abbreviations}

GDP: Gross domestic product; SES: Socioeconomic status; STEM: Science, technology, engineering, mathematics.

\section{Competing interests}

The authors declare that they have no competing interests.

\section{Authors' contributions}

Both authors, BH and LS, shared all responsibilities related to research, analysis, and drafting of this manuscript. All authors read and approved the final manuscript

\section{Author details}

'University of Southern California, 3470 Trousdale Parkway, Los Angeles, CA 90089, USA. ${ }^{2}$ Boise State University, 1910 University Drive, Boise, Idaho 83725, USA.

Received: 8 January 2013 Accepted: 8 January 2013

Published: 26 March 2013

\section{References}

Allen, M. (2005). Eight questions about teacher recruitment and retention: What does the research say? Education Commission of the States. http://www.ecs.org/html/educationissues/teachingquality/trrreport/home/ index.asp. Accessed 15 June 2012.

Alliance for Excellent Education. (2012). High school state cards. http://www. all4ed.org/about_the_crisis/schools/state_cards. Accessed 15 June 2012

Alters, BJ, \& Alters, SM. (2001). Defending evolution: a guide to the creation/ evolution controversy. Sudbury, MA: Jones \& Bartlett.

Carnevale, AP, Smith, N, \& Melton, M. (2011). STEM. Georgetown University Center on Education and the Workforce. http://cew.georgetown.edu/STEM/. Accessed 15 June 2012.

Dobzhansky, T. (1973). Nothing in biology makes sense except in the light of evolution. American Biology Teacher, 35, 125-129.

Domhoff, GW. (2012). Who rules America: wealth, income, and power. http://www2. ucsc.edu/whorulesamerica/power/wealth.html. Accessed 15 June 2012.

Fail, J. (2008). A no-holds-barred evolution curriculum for elementary and junior high school students. Evolution: Education and Outreach, 1(1), 56-64.

Gould, SJ. (2002). The structure of evolutionary theory. Cambridge, MA: Harvard University Press.

Heddy, BC, \& Nadelson, LS. (2012). A global perspective of the variables associated with acceptance of evolution. Evolution: Education and Outreach, $5,412-418$.

Jaumotte, F, Lall, S, \& Papageorgiou, C. (2008). Rising Income Inequality, Technology or Trade and Financial Globalisation? IMF Working Papers, no. WP/08/185.

Mayr, E. (1982). The growth of biological thought: diversity, evolution and inheritance. Cambridge, MA: Harvard University Press.

Miller, JD, Scott, EC, \& Okamoto, S. (2006). Public acceptance of evolution. Science, 313, 765-766.

Miller, KR. (2008). Only a theory. Evolution and the battle for America's soul. New York: Penguin Group.

Nadelson, LS, \& Sinatra, GM. (2009). Educational professionals understanding and acceptance of evolution. Journal of Evolutionary Psychology, 7(4), 490-516.

Nadelson, LS, \& Southerland, SA. (2010). Examining the interaction of acceptance and understanding: How does the relationship change with a focus on macroevolution? Evolution: Education and Outreach, 3, 82-88.

Oser, F, \& Reich, H. (1990). Moral judgment, religious judgment, world view, and logical thought: a review of their relationship part one. British Journal of Religious Education, 12(2), 94-101.

Pewforum.org. (2010). U.S. religious landscape survey. http://www.pewforum.org/ How-Religious-Is-Your-State-.aspx. Accessed 15 June 2012.

Rosengren, KS, Brem, SK, Evans, EM, \& Sinatra, GM (Eds.). (2012). Evolution challenges: integrating research and practice in teaching and learning about evolution. Oxford University Press, USA.
Rutledge, ML, \& Mitchell, MA. (2002). High school biology teachers' knowledge structure, acceptance \& teaching of evolution. American Biology Teacher, 64(1), 21-27.

Scott, EC. (2005). Evolution vs. creationism: an introduction. Berkeley, CA: University of California Press.

Scribner, JP. (1999). Professional development: untangling the influence of work context on teacher learning. Educational Administration Quarterly, 35(2), 238-266.

Sinatra, GM, \& Nadelson, LS. (2010). Science and religion: opposite ends of core epistemological continua? In R Taylor \& M Ferrari (Eds.), Epistemology and science education: understanding the evolution vs. Intelligent design controversy (pp. 173-194). New York: Routledge.

Sustersic, R. (2007). The impacts of religion and education on belief in evolution. Andrew Young School of Policy Studies. Department of Economics. (pp. 1-25)

Tyson, W, Lee, R, Borman, KM, \& Hanson, MA. (2007). Science, Technology, Engineering, and Mathematics (STEM) pathways: high school science and math coursework and post secondary degree attainment. Journal of Education for Students Placed at Risk, 12(3), 243-270.

United States Census Bureau. (2011). http://www.census.gov/compendia/statab/ cats/education.html. Accessed 15 June 2012.

United States Department of Commerce, Bureau of Economic Analysis. (2011). http://www.bea.gov/iTable/iTable.cfm?Req|D=70\&step=1\&isuri=1\&acrdn=1. Accessed 15 June 2012.

doi:10.1186/1936-6434-6-3

Cite this article as: Heddy and Nadelson: The variables related to public acceptance of evolution in the United States. Evolution: Education and Outreach 2013 6:3.

\section{Submit your manuscript to a SpringerOpen ${ }^{\odot}$ journal and benefit from:}

- Convenient online submission

- Rigorous peer review

- Immediate publication on acceptance

- Open access: articles freely available online

- High visibility within the field

- Retaining the copyright to your article

Submit your next manuscript at $>$ springeropen.com 